\title{
Analysis of Dysphagia Handicap Index in Stroke Patients and Associated Factors
}

\author{
Han Kyeol Kim ${ }^{\mathrm{a}}$, HyangHee Kim ${ }^{\mathrm{a}, \mathrm{b}}$, Seong Hee Choi ${ }^{\mathrm{c}}$, Deog Young Kim ${ }^{\mathrm{b}}$ \\ ${ }^{a}$ Graduate Program in Speech Language Pathology, Yonsei University, Seoul, Korea \\ ${ }^{b}$ Department and Research Institute of Rehabilitation Medicine, Yonsei University College of Medicine, Seoul, Korea \\ 'Department of Audiology and Speech-Language Pathology, Catholic University of Daegu, Gyeongsan, Korea
}

\author{
Correspondence: Deog Young Kim, MD, PhD \\ Department and Research Institute of \\ Rehabilitation Medicine, Yonsei University College \\ of Medicine, 50-1 Yonsei-ro, Seodaemun-gu, Seoul \\ 03722 , Korea \\ Tel: $+82-2-2228-3714$ \\ Fax: +82-2-363-2795 \\ E-mail: kimdy@yuhs.ac
}

Received: July 25, 2018

Revised: August 9, 2018

Accepted: August 9, 2018

This work is based on a part of the first author's master's thesis from Yonsei University.

\begin{abstract}
Objectives: There have been many studies on swallowing-related quality of life; however, few studies have looked at a homogenous subject group or the influential factors in detail. Thus, this study aimed to analyze key factors of swallowing-related quality of life in stroke patients. Methods: Forty-five stroke patients answered the Dysphagia Handicap Index (DHI). The relationship between the $\mathrm{DHI}$ and demographic information, post-stroke condition, and swallowing-related index was examined. The key factors affecting the DHI were analyzed by stepwise multiple regression analysis. Results: The average DHI of stroke patients was higher than that of normal groups reported by previous studies. In subscale, the functional and physical score were higher than the emotional score. The DHI of stroke patients showed significant correlation with the post-onset time, the Korean Mini Mental State Examination (K-MMSE), the National Institutes of Health Stroke Scale (NIHSS), the Geriatric Depression Scale (GDS), the Penetration Aspiration Scale (PAS), the Functional Dysphagia Scale (FDS), and the American Speech-Language-Hearing Association National Outcomes Measurements System swallowing scale (ASHA NOMS). Among the swallowingrelated factors, FDS and PAS were the most influential factors, accounting for $66.3 \%$ of the DHI. When dealing with FDS sub-items, 'pharyngeal transit time,' 'bolus formation', 'coating of pharyngeal wall after swallow' showed the most influence, accounting for $60.2 \%$ of the DHI. Conclusion: The swallowing-related quality of life in stroke patients declined due to dysphagia. Swallowing functions significantly affected stroke patients' swallowing-related quality of life, and swallowing problems in the pharyngeal phase had more impact than those in the oral phase.
\end{abstract}

Keywords: Swallowing disorder, Dysphagia, Dysphagia Handicap Index (DHI), Stroke, Quality of life, VFSS, PAS, FDS, ASHA NOMS 삼킴(swallowing)은 음식물을 입안에서 인두를 거쳐 식도로 옮 기는 과정으로, 크게 구강 준비 단계, 구강 운반 단계, 인두 단계, 식 도 단계로 구분된다. 삼킴장애(dysphagia)는 여러 단계의 삼킴과정 중 하나 이상에 문제를 보이는 것을 말한다. 삼킴장애는 혈관성 질 환, 진행성 질환, 선천성 질환 등으로 인해 발병할 수 있는데(Kim, 2012), 이 중 뇌졸중은 삼킴장애를 보일 확률이 매우 높은 질환이 다. 뇌졸중이란 뇌혈관의 출혈 혹은 경색 등으로 급작스러운 신경 학적 장애 또는 의식장애가 발생하는 질환을 가리킨다. 뇌졸중 환
자의 삼킴장애 유병률은 연구에 따라 차이가 있으나, 급성기의 경우 $50 \%$ 이상의 높은 유병률을 보고하였다(Daniels, Ballo, Mahoney, \& Foundas, 2000; Groher \& Crary, 2011). 뇌졸중 환자는 흡인의 발 생률이 높고, 이로 인한 합병증으로 폐렴, 패혈증, 사망의 위험에 노 출될 수 있다(Teasell et al., 2018).

삼킴장애는 환자의 삶의 질(quality of life)에도 영향을 준다. 삼 킴이 어려우면 식사 시간 또는 여가 활동 등에 제약이 생겨 심리. 정 서적 건강 및 사회생활에도 악영향이 초래된다(Gustafsson \& Tib- 
bling, 1991). 삼킴장애는 자존감을 상실시키고 신체도식과 타인과 의 관계를 저해하며(Carrau \& Murry, 1999), 결과적으로 우울증까 지 유발할 수 있다(Odderson, Keaton, \& McKenna, 1995). 이처럼 삼킴장애는 환자의 신체 건강뿐만 아니라 심리적, 사회적으로도 큰 영향을 준다.

현대 의료서비스는 질병의 치료뿐만 아니라 궁극적으로 삶의 질 개선을 목표로 한다. 세계보건기구(World Health Organization, 2001)는 '건강'을 '신체적, 정신적, 사회적으로 완전히 안녕한 상태' 로 정의하였으며, '삶의 질’은 ‘한 개인이 자신이 속한 문화 및 가치 체계 내에서 그들 자신의 목표, 기대, 규범 및 관심과 관련된 각자의 상태에 대한 개인적인 지각'을 의미한다고 하였다. 이와 같이 '건강' 과 '삶의 질'은 주관적인 개념을 포함한다. 따라서 질병의 평가와 중 재에서 단순히 질병의 유무나 중증도를 다루는 것을 넘어, 환자가 느끼는 심리·정서적, 사회적 안녕을 살피는 것 또한 중요하다.

선행연구들은 삼킴장애가 삶에 미치는 어려움을 측정하는 척도 로서 자기 보고에 의한 주관적 평가의 중요성을 강조하였다(Bandeira et al., 2008; Plowman-Prine et al., 2009). 주관적 평가도구를 활용한 여러 선행연구에서 삼킴장애 환자군은 정상군보다 낮은 삶 의 질을 보고하였다(Belafsky et al., 2008; Dwivedi et al., 2010; Govender et al., 2012; Kim, Kim, Kim, \& Cho, 2013; Manor, Giladi, Cohen, Fliss, \& Cohen, 2007; McHorney et al., 2002; Silbergleit, Schultz, Jacobson, Beardsley, \& Johnson, 2012). 현재까지 삼킴 관 련 삶의 질에 관한 연구가 다수 진행되었지만, 동질적(homogeneous) 질환의 환자군을 대상으로 하거나 삼킴 관련 변인을 세분화하여 상대적 영향력을 분석한 연구는 드물었다.

이에 본 연구에서는 삼킴장애지수(Dysphagia Handicap Index, $\mathrm{DHI}$ )를 활용하여 삼킴 관련 삶의 질의 주요 변인들을 구체적으로 살펴보고자 하였다. 뇌졸중 환자군의 일반적 특성, 뇌졸중 후 상태, 삼킴 관련 지표와 $\mathrm{DHI}$ 간의 관계를 살펴보고, $\mathrm{DHI}$ 에 대한주요 변 인들의 상대적 영향력을 알아보았다. 이를 통해 삼킴 관련 삶의 질 에 영향을 미치는 주요 변인을 분석하고 향후 연구 및 임상에 반영 할 수 있는 기초 자료를 마련하는 데 목적을 두었다. 구체적인 연구 문제는 다음과 같다.

1) 뇌졸중 환자의 일반적 특성, 뇌졸중 후 상태, 삼킴 관련 지표에 따른 DHI는 어떠한가?

2) 뇌졸중 환자의 일반적 특성, 뇌졸중 후 상태, 삼킴 관련 지표와 $\mathrm{DHI}$ 간의 상관관계는 어떠한가?

3) 뇌졸중 환자의 삼킴 기능이 DHI에 미치는 상대적 영향력은 어떠한가?

\section{연구방법}

\section{연구대상}

본 연구의 대상은 (1) 재활의학과 혹은 신경과 전문의에 의해 뇌 졸중으로 진단받고, (2) 신촌 세브란스병원에 입원 중 순차적으로 비디오투시조영삼킴검사(videofluoroscopic swallowing study, VFSS)를 시행한 뇌졸중 환자 45 명이었다. DHI의 다섯 문항을 실시 하였을 때 의사소통 문제로 설문이 불가한 것으로 판단되는 경우 는 대상에서 제외하였다.

대상자 성별은 남성 35 명, 여성 10 명이었다. 연령은 35-93세의 범 위로 평균 $64.6 \pm 13.3$ 세였으며, 65 세를 기준으로 청년층 65 세 미 만)은 25 명, 노년층(65세 이상)은 20 명이었다. 진단명은 뇌출혈 12 명, 뇌경색 33명이었다. 병소는 소뇌천막(tentorium cerebelli)을 기 준으로 천막상 28 명, 천막하 17 명이었으며, 손상 반구로는 좌반구 17 명, 우반구 18 명, 양반구는 10 명이었다. 유병기간은 3-1,864일의 범위로 평균 $126.56 \pm 292.326$ 일이었고, 급성기 3 개월 기준으로 3 개월 미만은 31 명, 3 개월 이상은 14 명이었다(Table 1).

뇌졸중 후 상태 관련 지표인 한국판 간이정신상태검사(Korean Mini Mental State Examination, K-MMSE) 점수는 평균 23.00土 5.580점, 미국국립보건원 뇌졸중 척도(National Institutes of Health Stroke Scale, NIHSS)는 평균 7.91 \pm 6.134점, 수정 바델 지수(Modified Barthel Index, MBI)는 평균 35.11 \pm 24.686 점, 기능적 보행 지 수(Functional Ambulation Classification, FAC)는 평균 .76 \pm 1.090

Table 1. Demographic information of the stroke patients $(N=45)$

\begin{tabular}{ll}
\hline Variable & $\mathrm{N}(\%)$ \\
\hline Gender & \\
Male & $35(77.8)$ \\
Female & $10(22.2)$ \\
Age & \\
Young & $25(55.6)$ \\
Elderly & $20(44.4)$ \\
Diagnosis & \\
Hemorrhage & $12(26.7)$ \\
Infarction & $33(73.3)$ \\
Lesion & \\
Supratentorial & $28(62.2)$ \\
Infratentorial & $17(37.8)$ \\
Left & $17(37.8)$ \\
Right & $18(40.0)$ \\
Both & $10(22.2)$ \\
Post-onset time (mo) & \\
$<3$ & $31(68.9)$ \\
$\geq 3$ & $14(31.1)$ \\
\hline
\end{tabular}


Han Kyeol Kim, et al. • Analysis of Dysphagia Handicap Index in Stroke Patients and Associated Factors

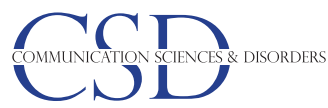

Table 2. Post-stroke condition and swallowing function of the stroke patients

\begin{tabular}{lc}
\hline Variable & Mean \pm SD (range) \\
\hline Post-stroke condition & \\
K-MMSE & $23.00 \pm 5.580(13-30)$ \\
NIHSS & $7.91 \pm 6.134(0-23)$ \\
MBI & $35.11 \pm 24.686(0-97)$ \\
FAC & $.76 \pm 1.090(0-5)$ \\
GDS & $11.76 \pm 8.488(0-29)$ \\
Swallowing function & \\
PAS & $3.69 \pm 2.618(1-8)$ \\
FDS & $35.47 \pm 12.952(18-79)$ \\
ASHA-NOMS & $5.22 \pm 1.906(1-7)$ \\
\hline
\end{tabular}

K-MMSE = Korean Mini-Mental State Examination; NIHSS= National Institutes of Health Stroke Scale; $\mathrm{MBI}=$ Modified Barthel Index; $F A C=$ Functional Ambulation Classification; GDS = Geriatric Depression Scale; ASHA-NOMS=American SpeechLanguage-Hearing Association National Outcomes Measurements System swallowing scale.

점, 노인우울척도(Geriatric Depression Scale, GDS)는 평균 $11.76 \pm$ 8.488 점이었다.

삼킴 관련 지표인 침습흡인척도(Penetration Aspiration Scale, $\mathrm{PAS}$ )는 평균 $3.69 \pm 2.618$ 단계, 기능적 삼킴장애척도(Functional Dysphagia Scale, FDS)는 평균 $35.47 \pm 12.952$ 점, ASHA NOMS 삼 킴척도(American Speech-Language-Hearing Association National Outcomes Measurements System Swallowing Scale)는 평균 5.22 \pm 1.906 단계였다(Table 2).

\section{연구도구 및 절차}

일반적 특성

재활의학과 전문의나 치료사에 의해 평가된 지표를 이용하여 대 상자에 관한 일반적인 정보(성별, 연령, 진단명, 병소, 유병기간)를 조사하였다.

\section{뇌졸중 후 상태}

재활의학과 전문의나 치료사에 의해 평가된 지표를 이용하여 뇌 졸중 후 상태에 관한 정보를 조사하였다. 단, 보고된 정보가 없는 경우에는 연구자가 직접 실시하여 측정하였다.

\section{한국판간이정신상태검사(K-MMSE)}

한국판 간이정신상태검사(K-MMSE)는 Folstein, Folstein과 $\mathrm{McHugh}$ (1975)가 개발한 인지기능선별검사를 한국어로 번안한 것이다(Kang, $\mathrm{Na}, \& \mathrm{Hahn}, 1997)$. 시간 지남력(5점), 장소 지남력(5 점), 기억등록(3점), 주의집중과 계산(5점), 기억회상(3점), 언어(8 점), 시공간 구성(1점)으로 이루어져 있다. 총점은 30점으로, 24점
이상은 정상, 20-23점은 경도 인지장애, 10-19점은 중등도 인지장 애, 9점 이하는 심한 인지장애로 구분한다.

\section{미국국립보건원 뇌졸중척도(NIHSS)}

미국국립보건원 뇌졸중척도(NIHSS)는 뇌졸중 후 중증도를 정 량적으로 측정하는 도구로, 국내에는 한글판 NIHSS가 마련되어 있다(Lee et al., 2004). 의식 수준, 응시, 시야, 안면 마비, 팔다리의 근력, 운동실조, 감각, 언어, 구음장애, 무시의 총 11 개 항목으로 구 성되어 있다. 0 점은 정상, 1-4점은 경도, 5-15점은 중등도, 16-20점 은 중등도-고도, 21-42점은 고도의 중증도로 구분한다.

수정바델 지수 $(\mathrm{MBI})$

바델 지수(Barthel Index)는 일상생활 활동의 수행능력을 평가 하는 도구이다. 국내에는 제 5 판 수정 바델 지수(MBI)를 번안한 한 글판수정 바델 지수(Korean Modified Barthel Index)가 있다(Jung et al., 2007). 개인위생, 목욕하기, 식사하기, 용변처리, 계단 오르기, 옷 입기, 대변조절, 소변조절, 보행/의자차, 의자/침대 이동의 10 가지 일상생활 활동을 평가한다. 도움의 정도에 따라 각 1-5단계로 나누 어 각 점수를 측정한다. 총점은 100 점으로, 0 -24점은 전적 의존(total), 25-49점은 심도, 50-74점은 중등도, 75-89점은 경도, 90-99점은 최소 의존(minimal)으로 구분한다.

기능적보행지수(FAC)

기능적 보행 지수(FAC)는 매사추세츠 종합병원(Massachusetts General Hospital)에서 개발된 보행능력 검사도구이다(Mehrholz, Wagner, Rutte, Meissner, \& Pohl, 2007). 대상자의 걷는 형태를 관찰하 거나 간단한 질문을 하여 평가할 수 있다. 보행 시 필요로 하는 인적 도움의 정도에 따라 점수를 매기게 된다. 0-5점의 6점 척도로 구성되 며, 점수가 높을수록 독립적인 보행 능력이 좋은 것으로 정의한다.

\section{노인우울척도(GDS)}

노인우울척도(GDS)는 우울 수준을 평가할 수 있는 도구이다 (Sheikh \& Yesavage, 1986). GDS는 다른 우울척도에 비해 민감도 와 특이도가 높아 뇌졸중 후 우울 수준을 진단하는 데 유용한 것으 로 보고되었다(Kim et al., 2008). 총점은 30점이며 0-13점까지는 정 상, 14-18점은 경도, 19-21점은 중도, 22점 이상은 심도로 구분한다.

\section{삼킴 관련 지표}

VFSS 영상을 관찰하여 PAS 및 FDS를 평가하였으며, ASHA NOMS는 VFSS 후 재활의학과 전문의에 의해 결정된 사항을 참고 
하여 조사하였다.

\section{침습흡인척도 $(P A S)$}

침습흡인척도(PAS)는 후두 침습과 흡인을 객관적으로 측정할 수 있는 척도이다(Rosenbek, Robbins, Roecker, Coyle, \& Wood, 1996). VFSS를 바탕으로 침습 및 흡인의 정도, 음식물의 위치, 음식물이 노력에 의해 밖으로 나오는지의 여부 등을 확인한다. 총 8 단계로 나 뉘며, 숫자가 높을수록 침습 및 흡인의 정도가 심함을 의미한다.

\section{기능적 삼킴장애척도(FDS)}

기능적 삼킴장애척도(FDS)는 삼킴장애의 생리적 측면을 평가 하는 척도이다(Han, Paik, \& Park, 2001). VFSS에서 관찰되는 입술 폐쇄, 음식덩이 형성, 구강 잔여물, 구강 이동 시간, 인두 삼킴 유발, 후두 상승 및 후두덮개 폐쇄, 비강 역류, 후두개곡 잔여물, 조롱박 오목(이상동) 잔여물, 인두벽 코팅, 인두 이동 시간 등을 측정하여 구강 및 인두 단계의 삼킴 기능을 점수화한다. 총점은 100 점으로, 점수가 높을수록 중증도가 심함을 의미한다.

\section{ASHA NOMS 삼킴 척도}

미국언어청각협회(American Speech-Language-Hearing Association)에서 2003년에 발표한 ASHA NOMS로 임상적 삼킴장애 중증도를 평가할 수 있다. 본 척도는 환자의 식이 형태 및 방법에 따 라 I-VII단계로 구성된다. ASHA NOMS 상 I단계는 가장 중한 상태 이며 VII은 가장 경한 상태를 나타낸다. I-VI단계는 저하군, VII단 계는 정상군으로 간주한다.

\section{삼킴장애지수 $(\mathrm{DHI})$}

삼킴장애지수(DHI)는 환자 보고형의 설문지로 삼킴장애로 인 한 어려움을 측정한다(Silbergleit et al., 2012). 총 25문항이며, 신체 적(physical) 영역 9문항, 기능적(functional) 영역 9문항, 정서적 (emotional) 영역 7문항으로 구성된다. 본 연구에서는 한국어판 $\mathrm{DHI}$ 를 사용하되(Choi, in press), 이 중 세 문항의 번역을 수정하였 다(Appendix 1). 각 설문 문항은 3 점 척도 $(0=$ 결코 그렇지 않다, $2=$ 때때로 그렇다, $4=$ 항상 그렇다)로 평가된다. 점수 범위는 0-100 점까지로 원점수가 높을수록 삼킴장애가 심한 것을 의미한다. 중 증도(severity)는 7 점 등간 척도 $(1=$ 정상, $7=$ 매우 심각 $)$ 로 삼킴장애 의 정도를 측정한다.

\section{검사-재검사 신뢰도}

검사-재검사 신뢰도를 위해 전체 표본의 $10 \%$ 를 무작위로 선정하
여 DHI와 삼킴 관련 척도를 재평가하였다. DHI에 대한 검사-재검 사 신뢰도는 94.4\%였다. 삼킴 관련 척도인 PAS, FDS, ASHA NOMS 는 모두 $100 \%$ 의 검사-재검사 신뢰도를 나타냈다.

\section{자료 분석}

첫째, 뇌졸중 환자의 DHI 점수 및 일반적 특성, 뇌졸중 후 상태, 삼킴 관련 지표의 분포를 빈도분석과 기술통계로 조사하였다. 둘 째, 뇌졸중 환자의 일반적 특성, 뇌졸중 후 상태, 삼킴 관련 지표에 따른 DHI 점수를 $t$-검정, 일원 분산분석(one-way analysis of variance, ANOVA), Kruskal-Wallis 검정으로 살펴보았다. 셋째, 뇌졸 중 환자의 일반적 특성, 뇌졸중 후 상태, 삼킴 관련 지표와 DHI 간 의 상관관계를 피어슨 상관분석(Pearson correlation analysis)으로 알아보았다. 넷째, 뇌졸중 환자의 삼킴 기능이 DHI에 미치는 상대 적 영향력을 단계적 다중회귀분석(stepwise multiple regression analysis)을 통해 조사하였다. 수집된 자료에 대한 통계분석은 SPSS version 24.0 을 사용했으며 통계학적 검정에 의한 유의수준은 .05 로 하였다.

\section{연구결과}

\section{뇌졸중 환자군의 DHI}

뇌졸중 환자군의 삼킴장애지수(DHI) 총점은 100 점 만점에 평 균 $21.42 \pm 18.43$ 점으로 나타났다. 신체적 $(\mathrm{P})$, 기능적 $(\mathrm{F})$ 영역 점수 는 총점 36 점 중 각각 평균 $8.18 \pm 6.10$ 점, $8.18 \pm 8.53$ 점이었고, 정서 적(E) 영역 점수는 총점 28 점 중 평균 $5.07 \pm 6.25$ 점으로, 기능적. 신체적 영역 점수가 정서적 영역 점수에 비해 높았다. 중증도(S)는 1-7점 척도상 평균 $2.78 \pm 1.70$ 점으로 조사되었다(Table 3).

\section{$\mathrm{DH}$ 와 관련 변인 간의 관계}

일반적 특성과 $\mathrm{DHI}$ 간의 관계

뇌졸중 환자군의 일반적 특성 중 유병기간에 따른 $\mathrm{DHI}$ 점수는 통계적으로 유의한 차이를 보였으나 $(p<.01)$, 성별, 연령, 진단명, 병

Table 3. Dysphagia Handicap Index score of the stroke patients

\begin{tabular}{lc}
\hline & Mean \pm SD (range) \\
\hline Total & $21.42 \pm 18.43(0-68)$ \\
Subscale & \\
Physical & $8.18 \pm 6.10(0-24)$ \\
Functional & $8.18 \pm 8.53(0-32)$ \\
Emotional & $5.07 \pm 6.25(0-22)$ \\
Severity & $2.78 \pm 1.70(1-6)$ \\
\hline
\end{tabular}


Han Kyeol Kim, et al. • Analysis of Dysphagia Handicap Index in Stroke Patients and Associated Factors

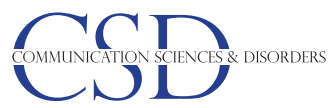

Table 4. Dysphagia Handicap Index score by demographic information

\begin{tabular}{lccc}
\hline Variable & Mean \pm SD (range) & Test statistic & $p$-value \\
\hline Gender & & & \\
Male & $23.49 \pm 19.676$ & 1.422 & .162 \\
Female & $14.20 \pm 11.094$ & & \\
Age & & & \\
$\quad$ Young & $24.72 \pm 20.687$ & 1.355 & .183 \\
$\quad$ Elderly & $17.30 \pm 14.615$ & & \\
Diagnosis & & & \\
Hemorrhage & $28.17 \pm 22.032$ & 1.502 & .141 \\
Infarction & $18.97 \pm 16.637$ & & \\
Lesion & & & \\
Supra-tentorial & $17.36 \pm 14.657$ & -1.774 & .088 \\
Infra-tentorial & $28.12 \pm 22.243$ & & \\
Left & $21.41 \pm 21.057$ & .701 & .502 \\
Right & $18.33 \pm 10.432$ & & \\
Both & $27.00 \pm 24.752$ & & \\
Post-onset time (mo) & & & \\
$<3$ & $15.35 \pm 12.800$ & $-3.075^{* *}$ & .007 \\
$\geq 3$ & $34.86 \pm 22.115$ & & \\
\hline
\end{tabular}

${ }^{* *} p<.01$.

Table 5. Correlations between Dysphagia Handicap Index and demographic information

\begin{tabular}{lcc}
\hline Variable & Coefficient & $p$-value \\
\hline Gender & -.212 & .162 \\
Age & .044 & .776 \\
Diagnosis & -.223 & .141 \\
Lesion & & \\
Supar/infra & .286 & .057 \\
Left/right & .002 & .992 \\
Post-onset time & $.495^{* *}$ & .001 \\
\hline
\end{tabular}

${ }^{* *} p<.01$.

소에 따른 DHI 점수는 통계적으로 유의한 차이를 보이지 않았다 ( $p>$.05) (Table 4). 유병기간 3개월 이상의 만성기 환자군은 급성기 환자군에 비해 $\mathrm{DHI}$ 점수가 높았다.

뇌졸중 환자군의 일반적 특성 중 유병기간과 $\mathrm{DHI}$ 점수는 높은 양의 상관관계를 보였으나 $(p<.01)$, 성별, 연령, 진단명, 병소는 DHI 점수와 유의한 상관관계를 보이지 않았다 $(p>.05)$ (Table 5). 즉, 유 병기간이 길수록 DHI 점수가 높은 것으로 나타났다.

\section{뇌졸중 후 상태와 $\mathrm{DH}$ 간의 관계}

뇌졸중 후 상태에 관한 지표 중 우울 수준(GDS)에 따른 $\mathrm{DHI}$ 점 수는 통계적으로 유의한 차이를 보였으나 $(p<.05)$, 인지 기능(K$\mathrm{MMSE})$, 뇌졸중 후 중증도(NIHSS), 일상생활 동작 수행력(MBI),
Table 6. Dysphagia Handicap Index score by post-stroke condition

\begin{tabular}{lrrcr}
\hline Variable & N & Mean \pm SD & Test statistic & $p$-value \\
\hline K-MMSE & & & 2.780 & .073 \\
$\quad$ Normal & 8 & $18.17 \pm 17.514$ & & \\
Mild & 13 & $31.08 \pm 15.135$ & & \\
$\quad$ Moderate & & & 5.722 & .126 \\
NIHSS & 5 & $12.40 \pm 8.989$ & & \\
Normal & 12 & $19.33 \pm 22.809$ & & \\
Mild & 21 & $18.76 \pm 11.480$ & & \\
Moderate & 7 & $39.43 \pm 23.741$ & & \\
Moderate-severe and over & & & 1.635 & .196 \\
MBI & 17 & $26.94 \pm 17.876$ & & \\
Total & 15 & $18.13 \pm 17.558$ & & \\
Severe & 10 & $13.80 \pm 14.528$ & & \\
Moderate & 3 & $32.00 \pm 31.749$ & & \\
Mild or less & & & .802 & .427 \\
FAC & 4 & $20.73 \pm 17.719$ & & \\
Dependent & 41 & $28.50 \pm 26.851$ & & \\
Independent & & & $4.544^{*}$ & .016 \\
GDS & 25 & $17.28 \pm 17.213$ & & \\
Normal & 10 & $17.40 \pm 12.929$ & & \\
Mild & 10 & $35.80 \pm 20.187$ & & \\
Moderate and over & & & \\
\hline
\end{tabular}

K-MMSE=Korean Mini-Mental State Examination; NIHSS= National Institutes of Health Stroke Scale; $\mathrm{MBI}=$ Modified Barthel Index; FAC=Functional Ambulation Classification; GDS = Geriatric Depression Scale. ${ }^{*} p<.05$.

Table 7. Correlation between $\mathrm{DH}$ and post-stroke condition

\begin{tabular}{lcc}
\hline Variable & Coefficient & $p$-value \\
\hline K-MMSE & $-.324^{*}$ & .030 \\
NIHSS & $.400^{* *}$ & .007 \\
MBI & -.067 & .660 \\
FAC & .257 & .088 \\
GDS & $.312^{*}$ & .037 \\
\hline
\end{tabular}

$\mathrm{DH}=$ Dysphagia Handicap Index; K-MMSE= Korean Mini-Mental State Examination; NIHSS = National Institutes of Health Stroke Scale; MBI = Modified Barthel Index; $F A C=$ Functional Ambulation Classification; GDS = Geriatric Depression Scale. ${ }^{*} p<.05,{ }^{* *} p<.01$.

보행 기능(FAC)에 따른 $\mathrm{DHI}$ 점수는 통계적으로 유의한 차이를 보 이지 않았다 $(p>.05)$ (Table 6). 우울 수준이 중도 이상인 환자군은 우울수준 정상군보다 DHI 점수가 높았다.

뇌졸중 후 상태에 관한 지표 중 뇌졸중 후 중증도(NIHSS) 및 우 울 수준(GDS)은 DHI 점수와 유의한 양의 상관관계가 있었고, 인 지 기능(K-MMSE)은 DHI 점수와 유의한 음의 상관관계가 있었다 $(p<.01)$. 반면 일상생활 동작 수행력(MBI) 및 보행 기능(FAC)은 $\mathrm{DHI}$ 점수와 유의한 상관관계가 나타나지 않았다(Table 7). 즉, 뇌 
졸중 후 중증도가 높을수록, 우울 수준이 높을수록, 인지 기능이 저하될수록 DHI 점수가 높았다.

\section{삼킴 관련 지표와 $\mathrm{DH}$ 간의 관계}

$\mathrm{PAS}$ 로 평가된 침습 및 흡인, FDS로 측정된 입술 폐쇄, 음식덩이 형성, 구강 잔여물, 구강 이동 시간, 삼킴 후 인두벽 코팅, 인두 이동
시간, ASHA NOMS상 식이 단계에 따른 DHI 점수는 통계적으로 유의한차이를 보였으나 $(p<.05), \mathrm{FDS}$ 로 측정된 후두 상승 및 후두 덮개 폐쇄, 후두개곡 잔여물, 조롱박오목 잔여물에 따른 DHI 점수 는 유의한 차이를 보이지 않았다( $p>$.05) (Table 8). FDS 하위 항목 중 인두 삼킴 유발은 모든 대상자가 '감소' 소견을 보였고, 비강 역 류는 한 명을 제외하고 모두 ‘정상’이었다.

Table 8. Dysphagia Handicap Index score by swallowing-related index

\begin{tabular}{|c|c|c|c|c|}
\hline Variable & $\mathrm{N}$ & Mean \pm SD & Test statistic & $p$-value \\
\hline PAS & & & $9.980^{* * *}$ & .000 \\
\hline Normal & 10 & $9.20 \pm 6.941$ & & \\
\hline Penetration & 23 & $18.35 \pm 17.020$ & & \\
\hline Aspiration & 12 & $37.50 \pm 17.376$ & & \\
\hline \multicolumn{5}{|l|}{ FDS } \\
\hline Lip closure & & & $-3.707^{* *}$ & .001 \\
\hline Normal & 43 & $19.49 \pm 16.383$ & & \\
\hline Abnormal & 2 & $63.00 \pm 7.0710$ & & \\
\hline Bolus formation & & & $-4.346^{* * *}$ & .000 \\
\hline Normal & 36 & $16.39 \pm 15.298$ & & \\
\hline Abnormal & 9 & $41.56 \pm 16.546$ & & \\
\hline Residue in oral cavity & & & $-3.196^{* *}$ & .003 \\
\hline Normal & 40 & $18.60 \pm 15.937$ & & \\
\hline Abnormal & 5 & $44.00 \pm 23.281$ & & \\
\hline Oral transit time & & & $-3.388^{* *}$ & .002 \\
\hline Normal & 27 & $14.59 \pm 14.388$ & & \\
\hline Abnormal & 18 & $31.67 \pm 19.418$ & & \\
\hline Laryngeal elevation and epiglottic closure & & & -1.523 & .135 \\
\hline Normal & 3 & $6.00 \pm 4.000$ & & \\
\hline Abnormal & 42 & $22.52 \pm 18.574$ & & \\
\hline Residue in valleculae & & & -1.209 & .233 \\
\hline Normal & 6 & $13.00 \pm 8.8320$ & & \\
\hline Abnormal & 39 & $22.72 \pm 19.235$ & & \\
\hline Residue in pyriform sinuses & & & -1.558 & .127 \\
\hline Normal & 15 & $15.47 \pm 17.800$ & & \\
\hline Abnormal & 30 & $24.40 \pm 18.296$ & & \\
\hline Coating of pharyngeal wall after swallow & & & $-3.338^{* *}$ & .002 \\
\hline Normal & 40 & $18.50 \pm 15.979$ & & \\
\hline Abnormal & 5 & $44.80 \pm 21.845$ & & \\
\hline Pharyngeal transit time & & & $-3.722^{* *}$ & .001 \\
\hline Normal & 30 & $14.47 \pm 13,459$ & & \\
\hline Abnormal & 15 & $35.33 \pm 19.518$ & & \\
\hline ASHA NOMS & & & $16.170^{* * *}$ & .000 \\
\hline Tube feeding & 4 & $45.00 \pm 21.260$ & & . \\
\hline Restricted diet & 24 & $26.17 \pm 17.820$ & & \\
\hline General diet & 17 & $9.18 \pm 7.780$ & & \\
\hline
\end{tabular}

PAS=Penetration Aspiration Scale; FDS=Functional Dysphagia Scale; ASHA-NOMS=American Speech-Language-Hearing Association National Outcomes Measurements System swallowing scale.

${ }^{* *} p<.01,{ }^{* * *} p<.001$. 
Table 9. Correlation between DHI and swallowing function

\begin{tabular}{lcc}
\hline Variable & Coefficient & $p$-value \\
\hline Penetration and aspiration level (PAS) & $.601^{* * *}$ & .000 \\
Functional dysphagia level (FDS) & $.755^{* * *}$ & .000 \\
Lip closure & $.492^{* *}$ & .001 \\
Bolus formation & $.598^{* * *}$ & .000 \\
Residue in oral cavity & $.438^{* *}$ & .003 \\
Oral transit time & $.459^{* *}$ & .002 \\
Laryngeal elevation and epiglottic closure & .226 & .135 \\
Residue in valleculae & $.440^{* *}$ & .002 \\
Residue in pyriform sinuses & $.322^{*}$ & .031 \\
Coating of pharyngeal wall after swallow & $.454^{* *}$ & .002 \\
Pharyngeal transit time & $.540^{* * *}$ & .000 \\
Dietary level (ASHA NOMS) & $-.581^{* * *}$ & .000 \\
\hline
\end{tabular}

$\mathrm{DH}=$ Dysphagia Handicap Index; PAS= Penetration Aspiration Scale; FDS= Functional Dysphagia Scale; ASHA-NOMS=American Speech-Language-Hearing Association National Outcomes Measurements System swallowing scale.

${ }^{*} p<.05,{ }^{* *} p<.01,{ }^{* * *} p<.001$.
흡인 집단은 정상 및 침습 집단보다 $\mathrm{DHI}$ 점수가 높았다. 입술 폐 쇄, 음식덩이 형성, 구강 잔여물, 삼킴 후 인두벽 코팅, 구강 및 인두 이동 시간 비정상 집단은 정상 집단에 비해 DHI 점수가 높았다. 또 한 비구강 식이 및 제한 식이 집단은 정상 식이 집단보다 $\mathrm{DHI}$ 점수 가 높았다.

삼킴 관련 지표와 $\mathrm{DHI}$ 간의 상관분석 결과, 침습 및 흡인 정도 (PAS), 기능적 삼킴장애 정도(FDS), 식이 단계(ASHA NOMS)는 모두 DHI 점수와 유의한 상관관계를 보였다 $(p<.001)$ (Table 9). 침 습 및 흡인 정도, 기능적 삼킴장애 정도는 $\mathrm{DHI}$ 점수와 높은 양의 상관관계가 있었고, 식이 단계는 DHI 점수와 높은 음의 상관관계 가 있었다. 즉, 침습 및 흡인 정도가 높을수록, 기능적 삼킴장애 정 도가 심할수록, 식이 제한이 많을수록 DHI 점수가 유의하게 높았 다. FDS 하위항목 중에서는 후두 상승 및 후두덮개 폐쇄를 제외하 고 모든 항목이 DHI 점수와 유의한 상관관계를 나타냈다.

Table 10. Multiple regression analysis of swallowing-related factors

\begin{tabular}{|c|c|c|c|c|c|c|c|}
\hline & Variable & B & SE & $\beta$ & $t$ & $p$-value & Remark \\
\hline Model 1 & FDS & 1.074 & .142 & .755 & $7.549^{* * *}$ & .000 & $\begin{array}{c}R^{2}=.570 \\
\text { Adj } R^{2}=.560 \\
F=56.988 \\
p<.001 \\
V I F=1.000\end{array}$ \\
\hline \multirow[t]{2}{*}{ Model 2} & FDS & .867 & .141 & .609 & $6.141^{* * *}$ & .000 & $\mathrm{R}^{2}=.663$ \\
\hline & PAS & 2.384 & .698 & .339 & $3.415^{* *}$ & .001 & $\begin{array}{c}\text { Adj } R^{2}=.647 \\
F=41.391 \\
p<.001 \\
V I F=1.228\end{array}$ \\
\hline
\end{tabular}

FDS= Functional Dysphagia Scale; PAS= Penetration Aspiration Scale. ${ }^{* *} p<.01,{ }^{* * *} p<.001$.

Table 11. Multiple regression analysis of VFSS findings

\begin{tabular}{|c|c|c|c|c|c|c|c|}
\hline & Variable & B & SE & $\beta$ & $t$ & $p$-value & Remark \\
\hline Model 1 & Bolus formation & 5.867 & 1.199 & .598 & $4.892^{* * *}$ & .000 & $\begin{array}{c}R^{2}=.358 \\
\text { Adj } R^{2}=.343 \\
F=23.930 \\
p<.001 \\
V I F=1.000\end{array}$ \\
\hline \multirow[t]{2}{*}{ Model 2} & Bolus formation & 4.759 & 1.106 & .485 & $4.305^{* * *}$ & .000 & \multirow{2}{*}{$\begin{array}{c}R^{2}=.508 \\
\text { Adj } R^{2}=.485 \\
F=21.712 \\
p<.001 \\
V I F=1.085\end{array}$} \\
\hline & Pharyngeal transit time & 3.908 & 1.089 & .404 & $3.589^{* *}$ & .001 & \\
\hline \multirow[t]{3}{*}{ Model 3} & Bolus formation & 3.814 & 1.053 & .389 & $3.624^{* *}$ & .001 & \multirow{3}{*}{$\begin{array}{c}\mathrm{R}^{2}=.602 \\
\text { Adj } \mathrm{R}^{2}=.572 \\
F=20.630 \\
p<.001 \\
\mathrm{VIF}=1.086-1.184\end{array}$} \\
\hline & Pharyngeal transit time & 4.013 & .993 & .415 & $4.043^{* * *}$ & .000 & \\
\hline & Coating of pharyngeal wall after swallow & 1.852 & .598 & .319 & $3.096^{* *}$ & .004 & \\
\hline
\end{tabular}

VFSS = videofluoroscopic swallowing study.

${ }^{* *} p<.01,{ }^{* * *} p<.001$. 


\section{$\mathrm{DH}$ 의 주요 삼킴 관련 변인}

일반적 삼킴 관련 변인

$\mathrm{DHI}$ 의 일반적 삼킴 관련 변인(FDS, PAS, ASHA NOMS)에 대한 단계적 다중회귀분석 결과, FDS와 PAS는 통계적으로 유의한 변인 이었으나 $(p<.01), \mathrm{ASHA}$ NOMS는 유의한 변인이 아닌 것으로 나 타났다( $p>.05)$. 모형 1 에서는 $\operatorname{FDS}$ 만 포함되었으며 $\mathrm{R}^{2}$ 은 .570 이었 다. 모형 2에서는 FDS에 PAS가 추가되었고, $\mathrm{R}^{2}$ 은 .663이었다(Table 10). 즉 일반적 삼킴 관련 변인 중 $\mathrm{DHI}$ 에 가장 영향력이 큰 변인은 기능적 삼킴장애 정도(FDS), 침습 및 흡인 정도(PAS) 순으로 나타 났으며, 이들 두 변인은 결합적으로 DHI를 $66.3 \%$ 설명하였다.

\section{VFSS Finding 관련 변인}

VFSS를 바탕으로 측정한 FDS 하위항목의 단계적 다중회귀분 석 결과, 음식덩이 형성, 인두 이동 시간, 삼킴 후 인두벽 코팅은 통 계적으로 유의한 변인이었다 $(p<.01)$. 반면 입술 폐쇄, 구강 잔여물, 구강 이동 시간, 후두 상승 및 후두덮개 폐쇄, 후두개곡 잔여물, 조 롱박오목 잔여물은 통계적으로 유의한 변인이 아니었다( $p>.05)$.

모형 1 에서는 음식덩이 형성만 포함되었으며 $\mathrm{R}^{2}$ 은. 358 이었다. 모 형 2에서는 음식덩이 형성에 인두 이동 시간이 추가되었고 $\mathrm{R}^{2}$ 은 .508이었다. 모형 3에서는 추가적으로 삼킴 후 인두벽 코팅이 포함 되어 $\mathrm{R}^{2}$ 은 .602 이었다(Table 11). VFSS상 나타난 기능적 삼킴장애 관련 변인 중 DHI에 가장 영향력이 큰 변인은 인두 이동 시간, 음식 덩이 형성, 삼킴 후 인두벽 코팅 순이었으며, 이들 변인은 결합적으로 $\mathrm{DHI}$ 를 $60.2 \%$ 설명하였다.

\section{논의 및 결론}

현재까지 주관적 삼킴 평가도구를 활용하여 삼킴 관련 삶의 질 을 살펴본 연구가 다수 진행되었지만, 동질적(homogeneous) 질환 의 환자군을 대상으로 하거나 삼킴 관련 변인을 세분화하여 상대 적 영향력을 분석한 연구는 드물었다. 이에 본 연구는 뇌졸중 환자 45 명을 대상으로 삼킴장애지수(DHI)를 조사한 후, 삼킴 관련 삶의 질에 영향을 미치는 주요 변인을 구체적으로 분석하였다.

뇌졸중 환자군의 $\mathrm{DHI}$ 점수는 선행연구에서 보고된 국내 정상 청년 및 노인군의 $\mathrm{DHI}$ 총점 및 모든 하위영역 점수에 비해 현저히 높았다(Kim, Choi, Lee, \& Choi, 2014). 즉, 뇌졸중 환자군은 삼킴 장애로 인해 삼킴 관련 삶의 질이 저하되었음을 알 수 있었다. 단, 선행연구의 환자군 점수와 비교할 때(Asadollahpour, Baghban, \& Asadi, 2015; Farahat, Malki, Mesallam, Bukhari, \& Alharethy, 2014; Oda et al., 2017) 본 연구에서 뇌졸중 환자군의 DHI 점수는
다소 낮은 편이었는데, 삼킴장애 여부에 따른 선별 없이 입원 후 순 차적으로 VFSS를 시행한 모든 뇌졸중 환자군을 대상으로 했기 때 문인 것으로 추정된다.

$\mathrm{DHI}$ 하위영역별로는 기능적 및 신체적 영역 점수가 정서적 영역 점수보다 높았다. 이로써 뇌졸중 환자들이 삼킴장애로 인해 기능 적 및 신체적, 정서적 측면 순으로 불편을 느낀다는 점을 확인하였 다. 환자들은 삼킴 문제로 인한 기능적 제약과 신체적 불편에 비교 적 더 민감하였으나, 심리·정서 상태 및 사회생활 측면에서도 영향 을 받고 있음이 드러났다. 이는 삼킴장애가 신체 건강뿐만 아니라 심리·정서적, 사회적 건강에도 악영향을 미친다는 선행연구와 일 치하는 결과였다(Carrau \& Murry, 1999; Gustafsson \& Tibbling, 1991; Odderson et al., 1995).

$\mathrm{DHI}$ 중증도 점수는 7점 척도상 정상-중간 정도에 해당하는 수 준이었는데, 설문 문항에서는 다양한 삼킴 문제를 보고하였으나 전 반적 중증도는 낮게 인식한 경우가 자주 있었다. 즉, 다수의 환자가 본인의 삼킴 문제를 인식하고 있음에도 불구하고 전반적 삼킴장애 중증도는 실제보다 경한 정도로 간주하였다. 따라서 임상에서 효과 적인 치료 계획을 세우고 환자의 협조를 독려하기 위해 이러한 주 관적 중증도를 고려하고 반영할 필요가 있을 것으로 사료된다.

일반적 특성과 DHI 간의 관계를 살펴본 결과, DHI는 유병기간 과 유의한 상관관계를 보였으나, 성별, 연령, 진단명, 병소와는 유의 한 상관관계를 보이지 않았다. DHI는 유병기간과 높은 양의 상관 관계를 보였으며, 유병기간이 3 개월 미만인 급성기 환자군과 3 개월 이상인 만성기 환자군의 DHI 점수 간에 유의한 차이가 있었다. 이 는 유병기간이 길수록 삼킴 관련 삶의 질이 낮았다는 선행연구결 과와 일치하였다(Cha, Jung, Chung, \& Lee, 2010). 반면 성별, 진단 명은 선행연구결과와 같이 삼킴 관련 삶의 질과 상관성이 없었다 (Moon, Kim, \& Won, 2016). 연령의 경우는 기존 연구결과와 불일 치하였는데(Kim et al., 2014), 본 연구가 다양한 연령대의 뇌졸중 환자를 대상으로 했다는 점에서 연령과의 상관성은 다소 소거된 것으로 사료된다. 병소는 연구마다 비일관적인 결과가 보고되었는 데(Lee \& Kim, 2007; Moon, Pyun, \& Kwon, 2012), 본 연구에서는 대상자 수가 제한적이었고 병소를 상세하게 분류하지 않아 상관성 이 충분히 측정되지 않았을 수 있다.

뇌졸중 후 상태와 $\mathrm{DHI}$ 간의 관계를 살펴본 결과, $\mathrm{DHI}$ 는 인지 기 능(K-MMSE), 뇌졸중 후 중증도(NIHSS), 우울 수준(GDS)과 유의 한 상관관계가 있었지만, 일상생활 동작 수행력(MBI), 보행 기능 (FAC)과는 유의한 상관관계를 보이지 않았다. DHI는 K-MMSE와 유의한 음의 상관관계로, 삼킴 기능이 인지 기능과 상관이 있다는 선행연구결과와 맥락을 같이하였다(Moon, Kim, \& Won, 2016). 인 
지가 낮을수록 입술 폐쇄, 혀 움직임, 후두 상승 등 삼킴 기전이 저 하되어 삼킴 기능이 감소하고 흡인의 위험이 높아질 수 있다(Kim,

Park, Oommen, \& McCullough, 2015; Robbins, Coyle, Rosenbek, Roecker, \& Wood, 1999). 또한 DHI는 NIHSS와 높은 양의 상관관 계로, 이는 뇌졸중 후 중증도가 심할수록 뇌졸중 후유증으로 인한 삼킴장애 정도가 증가한 것으로 해석할 수 있다. DHI는 GDS와 유 의한 음의 상관관계를 보였으며, 우울 수준 중도 이상의 환자군은 정상군보다 높은 $\mathrm{DHI}$ 점수를 보고하였다. 삼킴 문제가 신체적, 기 능적, 정서적 측면에서 불편을 야기하고 삶의 질을 저하시킬 수 있 다는 점에서 삼킴장애 정도가 우울 수준과 상관성을 보였을 가능 성이 있다. 반면 MBI는 선행연구결과와 동일하게 삼킴 관련 삶의 질과 상관성이 관찰되지 않았다(Moon et al., 2016). FAC는 보행 기 능 측정 도구로, 삼킴 관련 삶의 질과 유의한 관계가 없을 것이라는 일반적인 예측과 일치하는 결과를 보였다.

삼킴 관련 지표와 $\mathrm{DHI}$ 간의 관계를 살펴본 결과, $\mathrm{DHI}$ 는 침습 및 흡인 정도(PAS), 기능적 삼킴장애 정도(FDS), 식이 단계(ASHA $\mathrm{NOMS}$ )와 유의한 상관관계가 있었다. DHI는 PAS와 높은 양의 상 관관계를 보였으며, PAS 결과상 흡인이 있는 환자군은 침습 및 정 상군보다 DHI 점수가 높았다. 이는 흡인 경험이 삶의 질을 저하시 킨다는 선행연구결과와 일치하는 바이다(Humbert \& Robbins, 2008). 뇌졸중 환자는 삼킴 기관의 감각 및 운동능력 저하로 인해 침습 및 흡인의 발생률이 높아진다. 이로 인한 기침, 통증, 폐렴의 위 험 등은 원활한 구강 섭취를 방해하는 주요 원인이며, 따라서 삼킴 관련 삶의 질을 저하시킬 수 있다.

FDS 총점은 DHI와 높은 양의 상관관계를 보였으며, FDS 하위 항목 중 비강 역류, 인두 삼킴 유발, 후두 상승 및 후두덮개 폐쇄를 제외하고 나머지 항목은 모두 DHI와 유의한 상관관계를 나타냈다. 즉, 전반적인 기능적 삼킴장애 정도는 삼킴 관련 삶의 질과 상관성 이 있었다. 다만 비강 역류는 한 명을 제외하고 모두 ‘정상’이었으며, 인두 삼킴 유발은 모든 대상자가 '감소' 소견을 보여 분석에서 제외 되었다. 후두 상승 및 후두덮개 폐쇄 또한 대부분의 대상자가 '감소' 소견을 보였다. 일부 하위항목별 비교 집단의 표본수가 충분히 확 보되지 못함에 따라 뇌졸중 환자군에서 일반적으로 관찰된 기능 적 삼킴장애 항목과 $\mathrm{DHI}$ 간의 상관성이 통계적으로 과소 평가되 었을 가능성이 있다. 선행연구에 따르면 인두 삼킴 반사의 지연은 삼킴 전 흡인의 발생률을 증가시키고, 설골의 이동범위가 작거나 후두상승 및 후두덮개 폐쇄가 감소된 경우 삼킴 후 흡인의 위험이 높아질 수 있다(Hwang, Ha, \& Hwang, 2011; Kim et al., 2015; Kim, Kim, Kim, Moon, \& Kim, 2003). 흡인 여부가 삼킴 관련 삶의 질을 크게 좌우한다고 밝혀진 만큼, 뇌졸중 환자군에서 흡인 위험을 증
가시키는 삼킴 문제가 높은 확률로 존재함을 인식하고 고려할 필 요가 있을 것이다.

ASHA NOMS는 DHI와 높은 음의 상관관계를 보였으며, 비구 강 식이 및 제한 식이 환자군은 정상 식이 환자군보다 $\mathrm{DHI}$ 점수가 높았다. 이러한 결과는 경관급식이 삶의 질을 크게 저하시키는 요 인이며 식이 단계가 높을수록 삼킴 관련 삶의 질이 높았다는 선행 연구결과를 뒷받침하였다(Byun, 2013; Cha et al., 2010). 경관 급식 은 미각을 통한 즐거움을 상실시키고 신체적, 기능적, 정서적 측면 에서 주관적 장애 정도를 증가시켜 삼킴 관련 삶의 질을 저하시킬 수 있다. 더불어 연하제 사용 역시 식사 만족도를 크게 저하시키는 것으로 조사되었다.

$\mathrm{DHI}$ 의 일반적 삼킴 관련 변인 중 가장 큰 영향력을 갖는 변인은 FDS, PAS 순으로 나타났으며, 이 두 변인은 결합적으로 DHI를 $66.3 \%$ 설명하였다. 즉, 삼킴 관련 삶의 질에 대한 영향 변인으로서 기능적 삼킴장애 정도와 침습 및 흡인 정도가 가장 큰 영향력을 가 졌으며, 식이 단계의 영향력은 상대적으로 작았다. 선행연구에 따 르면 삼킴 관련 삶의 질은 식이 단계와 높은 상관성을 보였는데 (Byun, 2013; Cha et al., 2010), 본 연구결과는 환자군의 삼킴 관련 삶의 질을 결정하는 데 있어서 식이 단계의 중요성 이상으로 구강 및 인두 단계의 기능적 삼킴장애 정도와 침습 및 흡인 정도가 가질 수 있는 중요성을 시사하였다.

DHI의 VFSS Finding 관련 변인(FDS sub-items) 중 DHI에 가장 큰 영향력을 갖는 변인은 인두 이동시간, 음식덩이 형성, 삼킴 후 인 두벽 코팅 순이었으며, 이들 세 변인은 결합적으로 $\mathrm{DHI}$ 를 $60.2 \%$ 설 명하였다. 인두 이동시간은 인두의 감각 및 운동 저하로 인해 발생 하며 음식물이 인두 단계에 머무르는 시간을 증가시켜 일반적으로 침습 및 흡인과 높은 관련이 있다. 음식덩이 형성이 불충분할 시 식 사에 드는 시간 및 노력이 증가하며, 흡인의 위험을 높일 수 있다. 삼 킴 후 인두벽 코팅은 인두 근육의 마비, 인두의 심한 건조증 등으로 인해 발생하는데, 상대적으로 중한 정도의 삼킴장애를 보이는 환 자들에서 관찰되었다. 이는 목의 이물감을 유발할 수 있고 삼킴 후 흡인의 위험을 증가시켜 삼킴 관련 삶의 질을 저하시킨다. 이러한 결과는 인두 단계의 삼킴 문제가 구강 단계의 문제보다 삼킴 관련 삶의 질에 상대적으로 더 큰 영향을 끼침을 시사하였다.

본 연구는 주로 다양한(heterogeneous) 환자군을 포함한 선행연 구들과 달리 동질적(homogeneous) 질환 환자군의 $\mathrm{DHI}$ 를 분석하 여 유용한 자료를 마련하였다는 점에서 의의가 있다. 또한 국내에 서 아직 연구가 활발히 진행되지 않은 $\mathrm{DHI}$ 를 평가도구로 활용하 여 세부적인 삼킴 기능과 삼킴 관련 삶의 질 간의 관계를 밝혔다. 하 지만 대상자 전반에 공통되는 삼킴 문제가 존재하여 일부 삼킴 관 
련 변인의 영향력이 충분히 측정되지 못했을 수 있다는 제한점을 갖는다.

따라서 후속 연구에서는 연구대상자 수를 확대하여 연구 범위 를 확장하거나 삼킴 환자군과 정상군을 대조하는 연구를 진행할 수 있을 것이다. 또한 삼킴 평가범위를 식도 단계까지 포함하거나 검사식을 농도별로 세분화한 연구가 가능할 것이다. 마지막으로 $\mathrm{DHI}$ 의 임상적 실용성을 증진하기 위한 축소판 개발을 기대할 수 있다. DHI는 총 25문항으로, 기존의 평가 도구들에 비해 문항수가 감소되었음에도 불구하고 임상에서 여전히 한계점이 존재하였다. 따라서 $\mathrm{DHI}$ 축소판이 개발된다면 더욱 효율적인 주관적 삼킴 평 가도구로 활용될 것으로 기대된다.

\section{REFERENCES}

American Speech-Language-Hearing Association. (2003). National Outcomes Measurement System (NOMS): adult speech-language pathology user's guide. Rockville, MD: Author.

Asadollahpour, F., Baghban, K., \& Asadi, M. (2015). Validity and reliability of the Persian version of the dysphagia handicap index (DHI). Iranian Journal of Otorhinolaryngology, 27(80), 185-191.

Bandeira, A. K. C., Azevedo, E. H., Vartanian, J. G., Nishimoto, I. N., Kowalski, L. P., \& Carrara-de Angelis, E. (2008). Quality of life related to swallowing after tongue cancer treatment. Dysphagia, 23(2), 183-192.

Belafsky, P. C., Mouadeb, D. A., Rees, C. J., Pryor, J. C., Postma, G. N., Allen, J., \& Leonard, R. J. (2008). Validity and reliability of the Eating Assessment Tool (EAT-10). Annals of Otology, Rhinology \& Laryngology, 117(12), 919924.

Byun, M. K. (2013). Effect of dietary stages on swallowing function and quality of life for people with strokes (Master's thesis). Daegu University, Gyeongsan, Korea.

Carrau, R. L., \& Murry, T. (1999). Comprehensive management of swallowing disorders. San Diego, CA: Singular Publishing Group.

Cha, T. H., Jung, M. Y., Chung, B. I., \& Lee, T. Y. (2010). Correlation between dietary stages and quality of life assessed by SWAL-QOL in patients with dysphagia. The Journal of Korean Society of Occupational Therapy, 18, 6375.

Choi, S. H. (in press). Korean version of Dysphagia Handicap Index (K-DHI): validity and reliability. Manuscript in preparation.

Daniels, S. K., Ballo, L. A., Mahoney, M. C., \& Foundas, A. L. (2000). Clinical predictors of dysphagia and aspiration risk: outcome measures in acute stroke patients. Archives of Physical Medicine and Rehabilitation, 81(8), 1030-1033.

Dwivedi, R. C., Rose, S. S., Roe, J. W., Khan, A. S., Pepper, C., Nutting, C. M., ... \& Kazi, R. (2010). Validation of the Sydney Swallow Questionnaire (SSQ) in a cohort of head and neck cancer patients. Oral Oncology, 46(4), e10e14.

Farahat, M., Malki, K. H., Mesallam, T. A., Bukhari, M., \& Alharethy, S. (2014). Development of the arabic version of dysphagia handicap index (DHI). Dysphagia, 29(4), 459-467.

Folstein, M. F., Folstein, S. E., \& McHugh, P. R. (1975). "Mini-mental state”: a practical method for grading the cognitive state of patients for the clinician. Journal of Psychiatric Research, 12(3), 189-198.

Govender, R., Lee, M. T., Davies, T. C., Twinn, C. E., Katsoulis, K. L., Payten, C. L., ... \& Drinnan, M. (2012). Development and preliminary validation of a patient-reported outcome measure for swallowing after total laryngectomy (SOAL questionnaire). Clinical Otolaryngology, 37(6), 452-459.

Groher, M. E., \& Crary, M. A. (2011). Swallowing disorders. Seoul: Koonja Publishing.

Gustafsson, B., \& Tibbling, L. (1991). Dysphagia, an unrecognized handicap. Dysphagia, 6(4), 193-199.

Han, T. R., Paik, N. J., \& Park, J. W. (2001). Quantifying swallowing function after stroke: a functional dysphagia scale based on videofluoroscopic studies. Archives of Physical Medicine and Rehabilitation, 82(5), 677-682.

Humbert, I. A., \& Robbins, J. (2008). Dysphagia in the elderly. Physical Medicine and Rehabilitation Clinics of North America, 19(4), 853-866.

Hwang, W., Ha, S., \& Hwang, S. (2011). Displacement of the hyoid bone among normal, aspirated, and penetrated swallows in post-stroke patients with dysphagia. Korean Journal of Communication \& Disorders, 16, 372-387.

Jung, H. Y., Park, B. K., Shin, H. S., Kang, Y. K., Pyun, S. B., Paik, N. J., ... \& Han, T. R. (2007). Development of the Korean version of Modified Barthel Index (K-MBI): multi-center study for subjects with stroke. Journal of the Korean Academy of Rehabilitation Medicine, 31, 283-297.

Kang, Y., Na, D. L., \& Hahn, S. (1997). A validity study on the Korean MiniMental State Examination (K-MMSE) in dementia patients. Journal of the Korean Neurological Association, 15, 300-308.

Kim, D. Y., Park, C. I., Jung, K. J., Ohn, S. H., Lim, J. Y., \& Kwak, E. H. (2008). The comparison of post-stroke related depression scales. Journal of the Korean Academy of Rehabilitation Medicine, 32, 644-650.

Kim, G. H., Choi, S. H., Lee, K. J., \& Choi, C. H. (2014). Dysphagia handicap index and swallowing characteristics based on laryngeal functions in Ko- 
rean elderly. Phonetics and Speech Sciences, 6, 3-12.

Kim, H. (2012). Neurogenic speech-language disorders. Seoul: Sigmapress.

Kim, H. C., Kim, D. H., Kim, S. J., Moon, Y. S., \& Kim, H. C. (2003). Influencing factors on quality of life after stroke. Journal of Korean Geriatric Psychiatry, 7, 67-75.

Kim, J. Y., Kim, D. Y., Kim, H., \& Cho, S. R. (2013). A Validation Study of the Korean Version of the Swallowing-Quality of Life Scale. Communication Sciences \& Disorders, 18, 341-347.

Kim, Y., Park, T., Oommen, E., \& McCullough, G. (2015). Upper esophageal sphincter opening during swallow in stroke survivors. American Journal of Physical Medicine \& Rehabilitation, 94(9), 734-739.

Lee, H. J., \& Kim, H. (2007). A literature review on clinical variables of dysphagia after stroke. Journal of Speech \& Hearing Disorders, 16, 75-89.

Lee, K. M., Jang, Y. H., Kim, Y. H., Moon, S. K., Park, J. H., Park, S. W., ... \& Han, T. R. (2004). Reliability and validity of Korean version of National Institutes of Health Stroke Scale: multi-center study. Journal of the Korean Academy of Rehabilitation Medicine, 28, 422-435.

Manor, Y., Giladi, N., Cohen, A., Fliss, D. M., \& Cohen, J. T. (2007). Validation of a swallowing disturbance questionnaire for detecting dysphagia in patients with Parkinson's disease. Movement Disorders, 22(13), 1917-1921.

McHorney, C. A., Robbins, J., Lomax, K., Rosenbek, J. C., Chignell, K., Kramer, A. E., \& Bricker, D. E. (2002). The SWAL-QOL and SWAL-CARE outcomes tool for oropharyngeal dysphagia in adults. III. Documentation of reliability and validity. Dysphagia, 17(2), 97-114.

Mehrholz, J., Wagner, K., Rutte, K., Meissner, D., \& Pohl, M. (2007). Predictive validity and responsiveness of the functional ambulation category in hemiparetic patients after stroke. Archives of Physical Medicine and Rehabilitation, 88(10), 1314-1319.

Moon, H. I., Pyun, S. B., \& Kwon, H. K. (2012). Correlation between location of brain lesion and cognitive function and findings of videofluoroscopic swallowing study. Annals of Rehabilitation Medicine, 36(3), 347-355.

Moon, J. H., Kim, K. H., \& Won, Y. S. (2016). Correlations and comparison among swallowing function, dietary level, cognitive function, daily living according to characteristic in stroke patients with dysphagia. Journal of Rehabilitation Research, 20, 265-281.

Oda, C., Yamamoto, T., Fukumoto, Y., Nakayama, K., Sato, M., Murata, M., \& Kobayashi, Y. (2017). Validation of the Japanese translation of the Dysphagia Handicap Index. Patient Preference and Adherence, 11, 193-198.

Odderson, I. R., Keaton, J. C., \& McKenna, B. S. (1995). Swallow management in patients on an acute stroke pathway: quality is cost effective. Archives of Physical Medicine and Rehabilitation, 76(12), 1130-1133.

Plowman-Prine, E. K., Sapienza, C. M., Okun, M. S., Pollock, S. L., Jacobson, C., Wu, S. S., \& Rosenbek, J. C. (2009). The relationship between quality of life and swallowing in Parkinson's disease. Movement Disorders, 24(9), 1352-1358.

Robbins, J., Coyle, J., Rosenbek, J., Roecker, E., \& Wood, J. (1999). Differentiation of normal and abnormal airway protection during swallowing using the penetration-aspiration scale. Dysphagia, 14(4), 228-232.

Rosenbek, J. C., Robbins, J. A., Roecker, E. B., Coyle, J. L., \& Wood, J. L. (1996). A penetration-aspiration scale. Dysphagia, 11(2), 93-98.

Sheikh, J. I., \& Yesavage, J. A. (1986). Geriatric Depression Scale (GDS): recent evidence and development of a shorter version. In: T. Brink (ed.), Clinical gerontology: a guide to assessment and intervention (pp. 165-173). New York, NY: The Haworth Press.

Silbergleit, A. K., Schultz, L., Jacobson, B. H., Beardsley, T., \& Johnson, A. F. (2012). The dysphagia handicap index: development and validation. Dysphagia, 27(1), 46-52.

Teasell, R., Foley, N., Martino, R., Richardson, M., Benton, B., Janssen, S., \& Orenczuk, R. (2018). Dysphagia and aspiration following stroke. EvidenceBased Review of Stroke Rehabilitation, 1-71. http://www.ebrsr.com/sites/ default/files/v18-SREBR-CH15-NET.pdf

World Health Organization. (2001). International Classification of Functioning, Disability and Health: ICF. Geneva, Switzerland: Author. 
Appendix 1. Dysphagia Handicap Index (DHI)

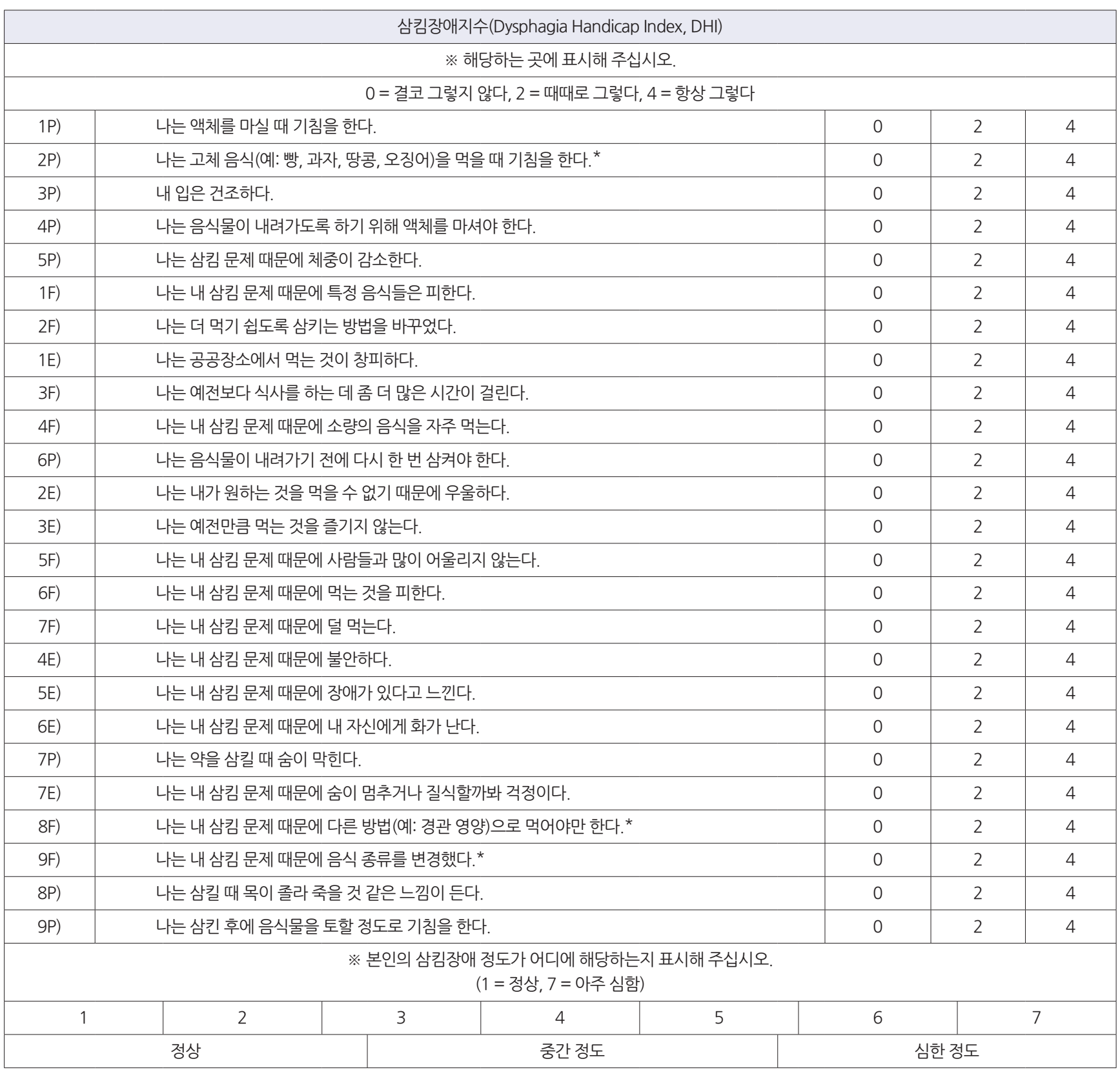

$\mathrm{P}=$ physical; $\mathrm{F}=$ functional; $\mathrm{E}=$ emotional.

${ }^{*}$ Choi (2014)의 연구에 수록된 한국어 번안본 중 2P, 8F, $9 F$ 문항의 번역이 수정됨. 


\section{국문초록}

\section{뇌졸중 환자의 삼킴장애지수(DHI)를 통한 삼킴 관련 삶의 질과 관련 변인 분석}

김한결 1 김향희 ${ }^{12} \cdot$ 최성희 ${ }^{3} \cdot$ 김덕용 ${ }^{2}$

${ }^{1}$ 연세대학교 대학원 언어병리학협동과정, ${ }^{2}$ 연세대학교 의과대학 재활의학교실, ${ }^{3}$ 대구가톨릭대학교 언어청각치료학과

배경 및 목적: 현재까지 삼킴 관련 삶의 질에 대한 연구가 다수 진행되었지만, 동일 질환의 환자군을 대상으로 하거나삼킴 관련 변인의 상대적 영향력을 살펴본 연구는 드물었다. 이에 본 연구는 뇌졸중 환자군의 삼킴 관련 삶의 질에 영향을 미치는 주요 변인을 분석하여 기초자료를 마련하고자 하였다. 방법: 뇌졸중 환자 45 명을 대상으로 삼킴장애지수(DHI)를 조사하여 삼킴 관련 삶의 질에 대한 주요 변인의 영향력을 알아보았다. 일반적 특성, 뇌졸중 후 상태, 삼킴 관련 지표와 DHI 간의 상관관계를 알아보고, 삼킴기능이 DHI에 미치 는 상대적 영향력을 다중회귀분석으로 조사하였다. 결과: 뇌졸중 환자군의 DHI 점수는 선행연구의 정상군 점수보다 높았으며, 기능 적·신체적 영역 점수가 정서적 영역보다 높았다. DHI는 유병기간, 인지기능(K-MMSE), 뇌졸중 후 중증도(NIHSS), 우울 수준(GDS), 침습·흡인 정도(PAS), 기능적 삼킴장애 정도(FDS), 식이단계(ASHA NOMS)와 유의한 상관관계를 보였다. 일반적 삼킴 관련 변인 중 DHI에 가장 영향력이 큰 변인은 FDS, PAS 순이었다. VFSS finding 관련 변인 중에서는 인두 이동시간, 음식덩이 형성, 삼킴 후 인두벽 코팅 순으로 큰 영향력을 보였다. 논의 및 결론: 뇌졸중 환자군은 삼킴 관련 삶의 질이 저하된 것으로 나타났다. 삼킴기능은 삼킴 관련 삶의 질에 유의한 영향을 끼쳤으며, 인두 단계의 문제가 구강 단계의 문제보다 상대적으로 큰 영향력을 보였다.

핵심어: 삼킴장애, 삼킴장애지수, 뇌졸중, 삶의 질, 비디오투시조영검사, PAS, FDS, ASHA NOMS

본 논문은 제1저자의 석사학위논문을 수정·보완한 것임.

\section{참고문헌}

강연욱, 나덕렬, 한승혜(1997). 치매환자들을 대상으로 한 K-MMSE의 타당도연구. 대한신경과학회지, 15, 300-308.

김근희, 최성희, 이경재, 최철희(2014). 한국 정상 노인층의 삼킴장애지수와 후두 기능에 따른 삼킴 특성. 말소리와음성과학, 6, 3-12.

김덕용, 박창일, 정강재, 온석훈, 임종엽, 곽은희(2008). 뇌졸중 후 우울증 척도 비교. 대한재활의학회지, 32, 644-650.

김자영, 김덕용, 김향희, 조성래(2013). Swallowing-Quality of Life (SWAL-QOL) 척도의 한국어판 번안. 언어청각장애연구, 18, 341-347.

김향희(2012). 신경언어장애. 서울: 시그마프레스.

김현철, 김도훈, 김세주, 문유선, 김흥철(2003). 뇌졸중 후 삶의 질에 영향을 미치는 요인. 노인정신의학, 7, 67-75.

문종훈, 김계호, 원영식(2016). 삼킴장애가 있는 뇌졸중 환자의 특성에 따른 삼킴기능, 식이수준, 인지기능, 일상생활의 비교 및 상관관계. 재활복지,

20, 265-281.

변민경(2013). 뇌졸중 환자의 식이단계가 연하기능과 삶의 질에 미치는 영향. 대구대학교 대학원 석사학위논문.

이경무, 장요한, 김연희, 문승국, 박주현, 박시운, 유희정, 이삼규, 전민호, 한태륜(2004). 한글판 미국 국립 보건원 뇌졸중 척도의 신뢰도 및 타당도. 대

한재활의학회지, 28, 422-435.

이현정, 김향희(2007). 뇌졸중에 기인한 삼킴장애의 임상적 변인에 관한 문헌연구. 언어치료연구, 16, 75-89.

정한영, 박병규, 신희석, 강윤규, 편성범, 백남종, 김세현, 김태현, 한태륜(2007). 한글판 수정바델지수(K-MBI)의 개발: 뇌졸중 환자 대상의 다기관 연

구. 대한재활의학회지, 31, 283-297.

차태현, 정민예, 정보인, 이택영(2010). 삼킴곤란자의 식이단계와 SWAL-QOL 척도를 통한 삶의 질과의 상관성. 대한작업치료학회지, 18, 63-75.

황우섭, 하승희, 황수진(2011). 삼킴장애를 보이는 뇌졸종환자의 침습 및 흡인에 따른 설골 이동범위 특성. 언어청각장애연구, 16, 372-387.

Michael E. Groher, Michael A. Crary (2011). 연하장애(대한연하재활학회 역). 서울: 군자출판사. 


\section{ORCID}

김한결(http://orcid.org/ 0000-0002-4425-0912); 김향희(http://orcid.org/0000-0003-4949-2512); 최성희(http://orcid.org/0000-0003-23656187); 김덕용(http://orcid.org/0000-0001-7622-6311) 